\title{
Rockburst Occurrence Mechanism Based on the Self-Sustaining Time-Varying Structure of Surrounding Rock
}

\author{
Baojie Fan $\mathbb{D}^{1,2}$ Fujun Zhao, ${ }^{1}$ Bin Wang $\mathbb{D},{ }^{1}$ Qiuhong Wu, ${ }^{1}$ and Zongtang Zhang ${ }^{1}$ \\ ${ }^{1}$ School of Resource \& Environment and Safety Engineering, Hunan University of Science and Technology, Xiangtan, \\ Hunan 411201, China \\ ${ }^{2} 414$ Geological Team, Hunan Geology Mineral Exploration and Development Bureau, Yiyang, Hunan 41300, China \\ Correspondence should be addressed to Bin Wang; wangbin@hnust.edu.cn
}

Received 4 June 2020; Revised 27 August 2020; Accepted 12 October 2020; Published 27 October 2020

Academic Editor: Qing Ma

Copyright (C) 2020 Baojie Fan et al. This is an open access article distributed under the Creative Commons Attribution License, which permits unrestricted use, distribution, and reproduction in any medium, provided the original work is properly cited.

Rockburst is one of the major disasters that threaten the safety of personnel and equipment underground and affect the normal production of the system. At present, there are many kinds of research on rockburst occurrence mechanisms, but most of them are based on statics and do not consider the time-varying effect of surrounding rock state. Regarding the stress state and characteristics changing with time of the surrounding rock support structure and the internal parameters after the tunnel excavation is analyzed qualitatively in this paper, the concept of the "self-sustaining time-varying structure of the surrounding rock" is put forward. The "self-sustaining time-varying structure of the surrounding rock" is regarded as a nonperiodic time-varying system with a single degree of freedom, then its dynamic characteristics are analyzed by using the momentum theorem of the particle system. The results show that when the mass of the self-sustaining time-varying structure changes with time and $(\mathrm{d} m / \mathrm{d} t)<0$, the rockburst may be induced by the free vibration with increasing amplitude. The faster the $(\mathrm{d} m / \mathrm{d} t)$ changes, the more violent the rockburst is. This explains the rockburst occurrence mechanism from a new angle and explains the phenomenon that most rockburst occurs when $\sigma_{\theta}$ was lower than $\sigma_{c}$ better.

\section{Introduction}

A rockburst is defined as damage to an excavation that occurs in a sudden or violent manner and is associated with a seismic event [1-4]. Rockburst can occur either during the excavation (known as strainbursts) or after excavation (known as impact-induced or delayed rockburst) based on the triggering factors in the form of rock slices, rock fall, and rock fragments ejection with roaring sound [5]. Because of the random and violent properties of rockburst, it is likely to cause serious casualty, mechanical damage, and economic losses [6-9]. Considering complex physical and mechanical properties of rock masses, geological conditions, and artificial disturbance factor, rockburst mechanism is very complicated, and it is a problem to perplex the world [10]. Up to now, the rockburst occurrence mechanism is unclear yet. Based on the situation above, researching the rockburst occurrence mechanism is urgent, and it has become the key to reduce and control rockburst.

Since 1980s, scholars had numerous researches on the rockburst occurrence mechanism. Ortlepp and Stacey [11] proposed five rockburst mechanisms: strainbursting, buckling, face crushing, virgin shear, and reactivated shear on existing faults or discontinuities. On this basis, Kaiser et al. [1] simplified the rockburst occurrence mechanism into three categories: buckling due to rock breakage, rock ejection due to earthquake energy transmission, and rock fall due to earthquake. By summarizing these rockburst mechanisms classifications, they are essentially divided into stiffness theory, energy theory, and strength theory.

In 1972, Blake [12] put forward the stiffness theory. Rockburst occurs when the rock mass stiffness is greater than environmental rock mass stiffness. According to the study of Kaiser and Cai [13], strainburst must has the 
following loading conditions: tangential stress has concentration on roadway surface, and the loading system stiffness must be soft. The rock falls in a sudden and violent manner when the loading system is softer than the rock mass stiffness.

$\mathrm{Xu}$ et al. [14] proposed the rockburst energy release rate (RBERR) by analyzing the triaxial unloading tests energy transfer under four different control conditions. RBERR was used to analyze the rockburst location and intensity in the potentially dangerous area. A. Kidybinski [15] uses the ratio, which is elastic deformation energy stored in rock samples divided by the strain energy consumed of plastic deformation and fragmentation, to determine the rockburst tendency. Mitri et al. [16] pointed out that rockburst may occur on the roadway surface when the rock reaches the energy storage limit. According to the researching by Kwasniewski and Wang [17], Wang and Park [18], rockburst occurrence depends on two conditions: first, the rock mass can store the considerable strain energy; second, the rock mass has stress concentration, and strain energy could be released violently. Liang et al. [19] carried out acoustic emission monitoring experiments of roadway rockburst under biaxial loading. The results show that when the horizontal load is added, the energy accumulated increases significantly during the rockburst incubation process. The time of particles ejection to violent ejection is short, and the energy release is accelerated. Xu [20] studied the rockburst occurrence conditions in underground engineering and found that, in the construction of hard rock with high in situ stress, the advancing hole and high-pressure water injection can prevent rockburst from three aspects. First, release the elastic strain energy stored in surrounding rocks in advance, and the maximum tangential stress is transferred to the interior of the surrounding rock. Second, high-pressure water injection can split, soften, and reduce the strength of surrounding rock. Third, high-pressure water injection can make the original cracks interconnect and expand, thus reducing the surrounding rock's ability to store elastic strain energy. The theory of residual energy dominates the current understanding of rockburst power sources and rockburst mechanism, which holds that the power source is derived from the difference between the energy consumed during rock failure and the elastic strain energy inside the rock. The energy theory does not take into account the factors of time and space and does not explain the destruction condition and the properties of the equilibrium state.

The strength theory was put forward by the early rockburst workers. It starts from the static equilibrium condition and takes various strength criteria as the judgement basis of rockburst. The Russenes rockburst criterion based on $\left(\sigma_{\theta} / \sigma_{c}\right)$ is widely used in rockburst prediction, that is, $\left(\sigma_{\theta} / \sigma_{c}\right)<0.20$ rockburst free, $0.20 \leq\left(\sigma_{\theta} / \sigma_{c}\right)<0.30$ weak rockburst, $0.30 \leq\left(\sigma_{\theta} / \sigma_{c}\right)<0.55$ medium rockburst, $\left(\sigma_{\theta}\right.$ $\left./ \sigma_{c}\right) \geq 0.55$ strong rockburst. According to the in situ stress measurement data of the Qinling tunnel and Taipingyi diversion tunnel, $\mathrm{Xu}$ et al. [21] calculated the tangential stress $\sigma_{\theta}$ of surrounding rocks. The results showed that $\left(\sigma_{\theta} / \sigma_{c}\right)$ was $0.2 \sim 0.3$, but both tunnels had strong rockburst. Although the stress redistribution induced by tunnel excavation can increase $\sigma_{\theta}$ near the surface, according to the more-coulomb criterion, the increase is not enough to burst the surrounding rock. Therefore, $\mathrm{Xu}$ et al. [22] believe that rockburst should have other inducing mechanisms besides static pressure failure.

At present, most scholars' studies are based on the rock statics theory, which concerns mainly the initial stress state of surrounding rock and the final result of the stress adjustment after excavation. The surrounding rock internal parameters of roadway and tunnel change with time after excavation. The external conditions of most research objects can change with time, such as the applied load, temperature, and energy. But the internal parameters are always considered to be constant in the research process, such as geometry, physical properties, and boundary conditions. According to the viewpoint in literature [23, 24], the study that focuses the objects internal parameters changing with time is called time-varying mechanics. The rockburst occurrence mechanism conforms to the characteristics of the time-varying mechanics. In this paper, the rockburst occurrence mechanism is studied in combination with the time-varying mechanics theory by analyzing the self-sustaining structure of surrounding rock after tunnel and tunnel excavation.

\section{The Self-Sustaining Time-Varying Structure of Surrounding Rock}

2.1. The Proposal of Self-Sustaining Time-Varying Structure of Surrounding Rock. According to modern roadway support theory, the surrounding rock and support structure form a cooperative bearing system after roadway excavation. In order to study the bearing ratio of surrounding rock and support structure, literature [25] used 3d geomechanical model test to simulate the tunnel through the weak fault based on the background of Xianglushan tunnel project. The results show that the surrounding rock bears most of the load, accounting for about $97 \%$. This indicates that some self-sustaining structure exists in the surrounding rock after roadway excavation.

After excavation, the surrounding rock of deep roadway will be in biaxial stress state instead of a triaxial stress state, as shown in Figure 1. The radial stress $\sigma_{r}$ unloads, and tangential stress $\sigma_{\theta}$ loads. The surrounding rock stress is redistributed.

For circular roadway, the tangential stress around the roadway is obtained by Cauchy's solution. That is [26],

$$
\sigma_{\theta}=(1-2 \cos 2 \theta) \sigma_{h}+(1+2 \cos 2 \theta) \sigma_{v},
$$

where $\sigma_{v}$ is the vertical crustal stress; $\sigma_{h}=k \sigma_{v}$ is the horizontal crustal stress.

For other section shapes roadway, the tangential stress around the roadway can be expressed as equation (2). That is [26],

$$
\sigma_{\theta}=\alpha \sigma_{h}+\beta \sigma_{v}=(k \alpha+\beta) \sigma_{v}
$$

where $\alpha$ and $\beta$ and are stress concentration factors, whose values are related to the section shape of the roadway. They 


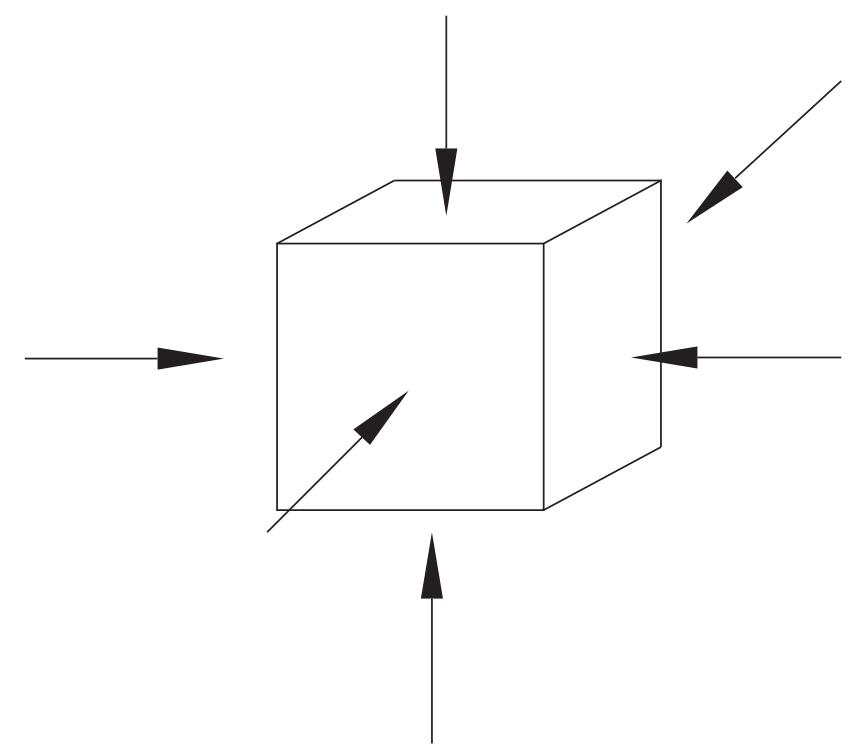

(a)

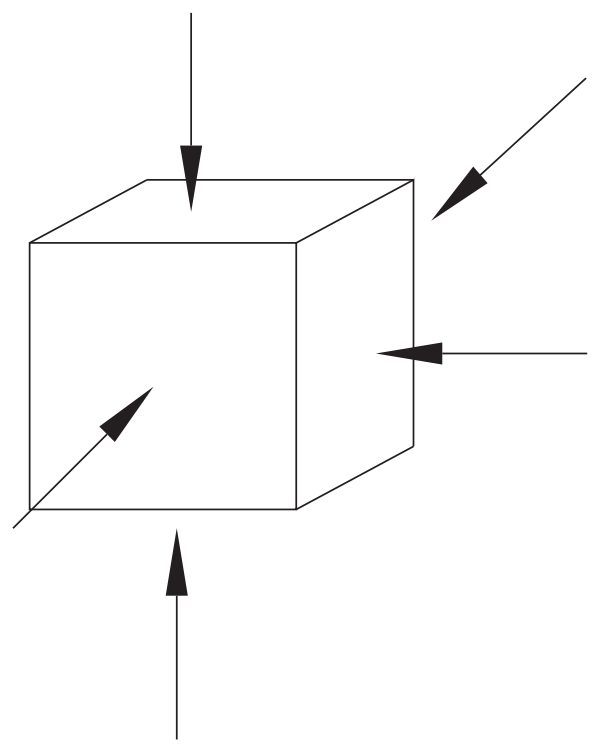

(b)

Figure 1: Stress state of surrounding rock before and after excavation. (a) Before excavation. (b) After excavation.

took different values at different positions around the roadway, which can be determined by elastic mechanics method or photoelastic test.

According to (1) and (2), the vertical crustal stress $\sigma_{v}$ and the tangential stress $\sigma_{\theta}$ around the roadway increase with the roadway buried depth growth. After the roadway excavation, the surrounding rock is destroyed. The peak value of tangential stress $\sigma_{\theta}$ shifts to the interior. The surrounding rock tends to expand to the free surface. The tensile stress appears on the roadway surface, which may lead to rockburst. Hou and Wang [27] proposed that rockburst may occur in the deeply buried roadway with the overlying strata effect considered only. The engineering example shows that the stress transition is related to the rockburst closely, which may be the power source inducing the rockburst. Combined with the rockburst stress evolution model in literature [28], the peak transition of tangential stress in the circular roadway can be obtained, as shown in Figure 2. The existing research on the rockburst occurrence mechanism is basically carried out for the stable state $(d)$, which is the final result of stress adjustment after excavation. Less attention is paid to the dynamic response of surrounding rock when the stress transitions from the initial state $(b)$ to the intermediate state $(c)$, and then from the intermediate state $(c)$ to the stable state $(d)$. It can be known from Figure 2 that, during the stress transition, the internal parameters of the surrounding rock system, such as the geometric shape, the physical and mechanical properties, the boundary state, and the energy state of the rock mass, all change with time. The rockburst problem has the characteristic of time-varying structural mechanics, in which the internal parameters of the structure vary with time. The time-varying mechanics theory can be applied to the study of the rockburst occurrence mechanism from a new perspective.

Many engineering examples show that weak jointed rocks do not have rockburst tendency, and rockburst mostly occurs in hard rock such as quartzite, granite, syenite, diorite, granodiorite, marble, and gneiss. Rockburst rock masses are brittle; that is, the rocks break sharply after reaching peak strength. According to Figure 2, the tangential stress of the initial state $(b)$ is also the initial state of the selfsustaining structure of surrounding rock. If this state can exist, it indicates that the surrounding rock has not been fractured after roadway excavation. However, the failure of surrounding rock is inevitable under high stress. If the failure of the surrounding rock is sharp, the tangential stress transition is also intense. Every fracture of the surrounding rock will lead to the boundary of the self-sustaining structure adjustment or change. From the perspective of physical properties of the rockburst rock, deep rock changes from brittleness to ductility under high stress, while it will vary from ductility to brittleness with excavation or unloading. Meanwhile, rock mass far away from the excavation roadway changes from brittleness to ductility [29]. Fang [30] proposed the maintenance theory of the primary and secondary bearing zones coordination. After excavation, the surrounding rock moves towards the free surface, leading to large deformation around the roadway. The first surrounding rock zone is generated within a certain range. Within a certain range, the surrounding rock produces the first tension zone. In the depth direction of the surrounding rock, outside the first tension zone, a compression zone appears, which is due to the self-supporting capacity of the surrounding rock. According to the measured data analysis and the similar materials simulation results, the tensile zone and the compression zone are generated alternately with time and gradually attenuate to the depth, as shown in Figure 3. It could be seen that the boundary and mechanical properties of the surrounding rock self-sustaining structure are changing at any time. According to the viewpoint of literature [31], the structure whose internal parameters including geometric shape, boundary state, and physical 


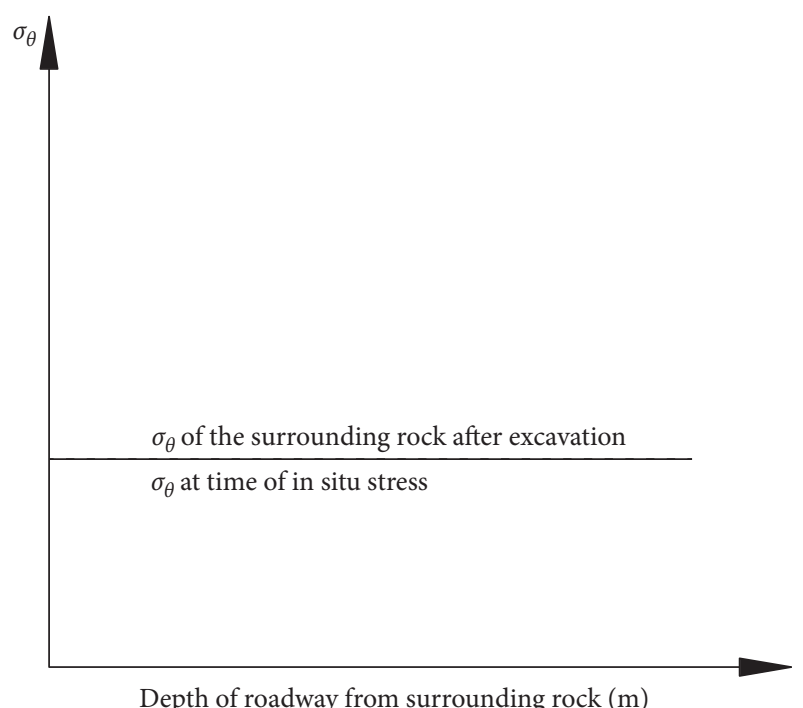

(a)

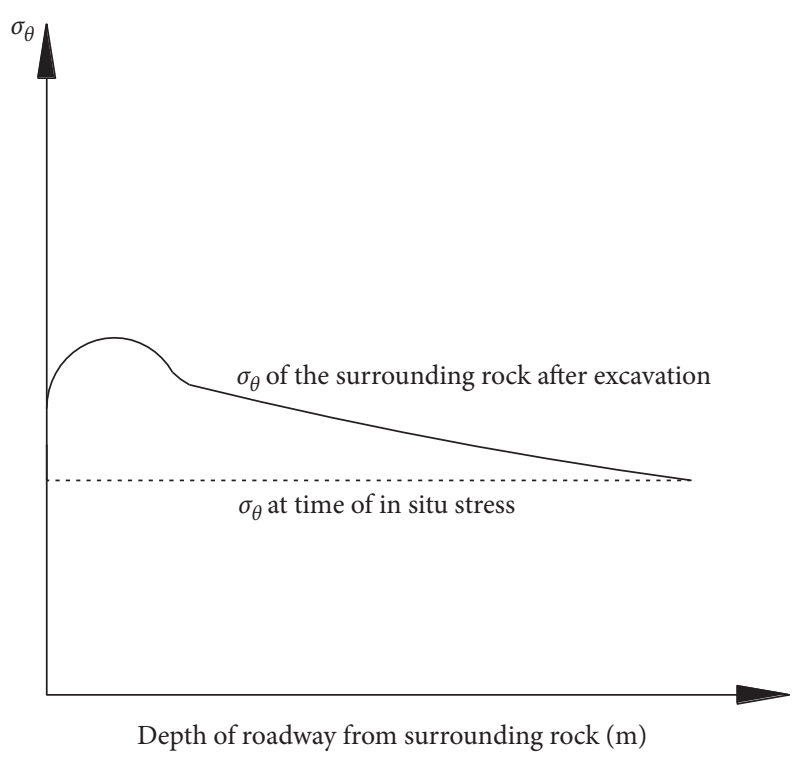

(c)

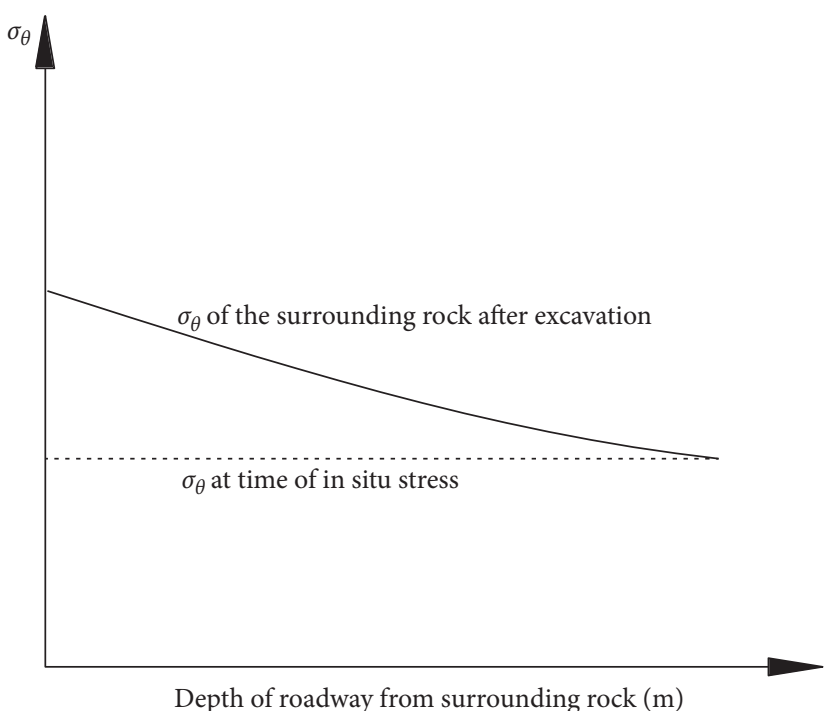

(b)

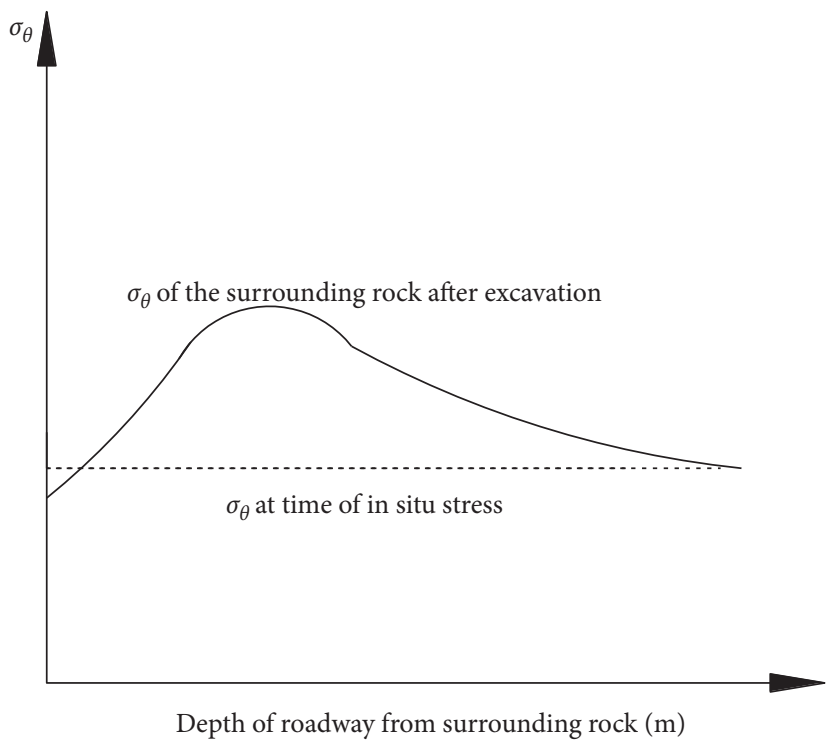

(d)

Figure 2: Tangential stress evolution model of rockburst. (a) The initial state. (b) The start state. (c) The intermediate state. (d) The steady state.

characteristics change with time is called "time-varying structure." This paper is mainly focused on the surrounding rock around the excavation roadway. Combining the study of rockburst mechanism, the concept of "surrounding rock self-sustaining time-varying structure" is introduced, and it is considered that rockburst is the process of surrounding rock self-sustaining time-varying structure adjustment under certain conditions.

2.2. Analysis of the Surrounding Rock Self-Sustaining TimeVarying Structure. According to Heim's hypothesis, the rock stress in the roadway is very high in all directions. The stress is related to the overlying rock mass, and all directions are almost equal. That is, the rock stress state of the deeply buried roadway is close to the hydrostatic pressure state. $\mathrm{Li}$ [32] studied the deformation and failure mechanism of circular roadway surrounding rock under different confining pressures. The results show that, under high confining pressure, the surrounding rock failure is mainly concentrated on the roadway roof and floor when the side pressure coefficient $K>1$; the surrounding rock failure is mainly concentrated on the two sides of the roadway when the side pressure coefficient $K<1$; the surrounding rock failure shows an obvious zonal fracture phenomenon when the side pressure coefficient $K=1$. Combining with the Heim hypothesis, it can be concluded that, in most cases, the side pressure coefficient $K=1$ in deep-buried roadway, and the zonal fracture is more common. Zhou et al. [33] proposed that the deep roadway surrounding rock will show the zone 


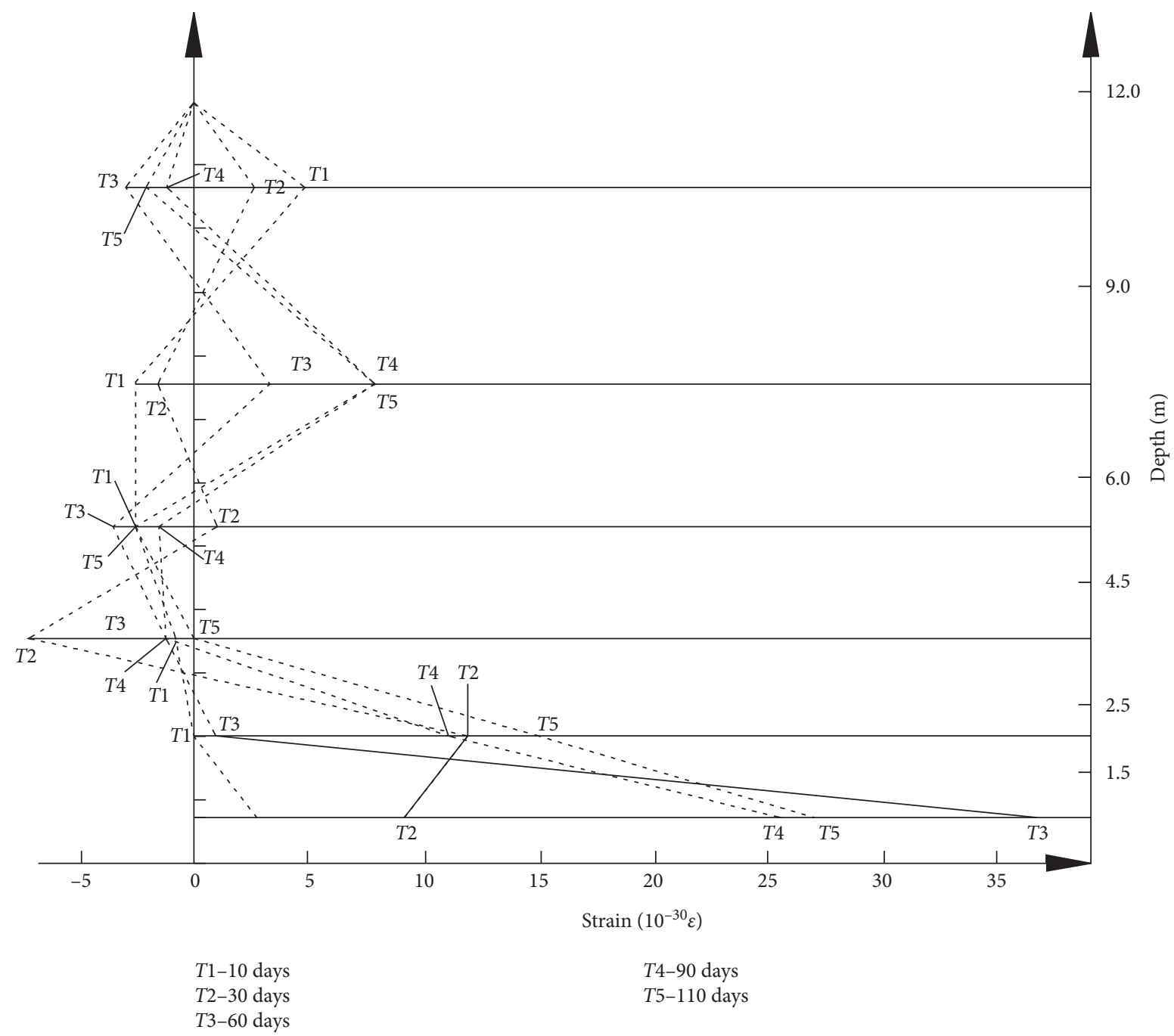

FIgURE 3: Tensile and compressive strain changed with time and hole depth in the surrounding rock [30].

fragmentation phenomenon after excavation or disturbance, which occurs alternately in the fractured zone and the nonfractured zone. Chen et al. [34] proposed that the fractured zone and elastic zone compose the bearing structure, which controls the overall bearing capacity of surrounding rock. Here, taking each nonfractured zone as the boundary and combining time-varying mechanics, the load-bearing structure formed by adjacent fractured zone and the nonfractured zone is called "the surrounding rock self-sustaining time-varying structure," as shown in Figure 4.

According to the example in the literature [35] and the deep rock strength criterion, a spherical roadway radius $R=4 \mathrm{~m}$, the in situ stress $q=100 \mathrm{MPa}$, the Poisson ratio $\mathrm{v}_{0}=0.1$, the elastic modulus $E=2000 \mathrm{MPa}$, the density of the $\operatorname{rock} \rho=2300\left(\mathrm{~kg} / \mathrm{m}^{3}\right)$, dynamic friction angle $\beta_{0}=18^{\circ}$ being set, fractured zone width, and quantity are shown in Table $1 . R_{0}$ is the inner boundary of the fractured zone. $R_{1}$ is the outer boundary of the fractured zone. $R_{1}-R_{0}$ is the width of the fractured zone. The distance between each fractured zone is the width of the nonfractured zone (Tables 2 and 3$)$.
When the buried depth is shallow and the ground stress level is low, the superposed stress field of excavation unloading and in situ stress is not enough to produce the second fractured zone. When the buried depth is large and the ground stress level is high, the stress is released, and the first fractured zone is generated after roadway excavation. The outer boundary of the fractured zone is equivalent to the new excavation boundary. When the redistribution stress field meets the strength criterion of deep rock, the second fractured zone is generated. This phenomenon continues until the redistribution stress no longer produces the fractured zone.

In conclusion, the mass and thickness of the selfsustaining time-varying structure of surrounding rock are determined by the in situ stress, roadway excavation duration, and surrounding rock lithology. The excavation speed is fast, the number of self-sustaining time-varying structures increases, and the thickness is greater. With low ground stress levels, there is only one self-sustaining time-varying structure of the surrounding rock after excavation. When the ground stress level is high, the 


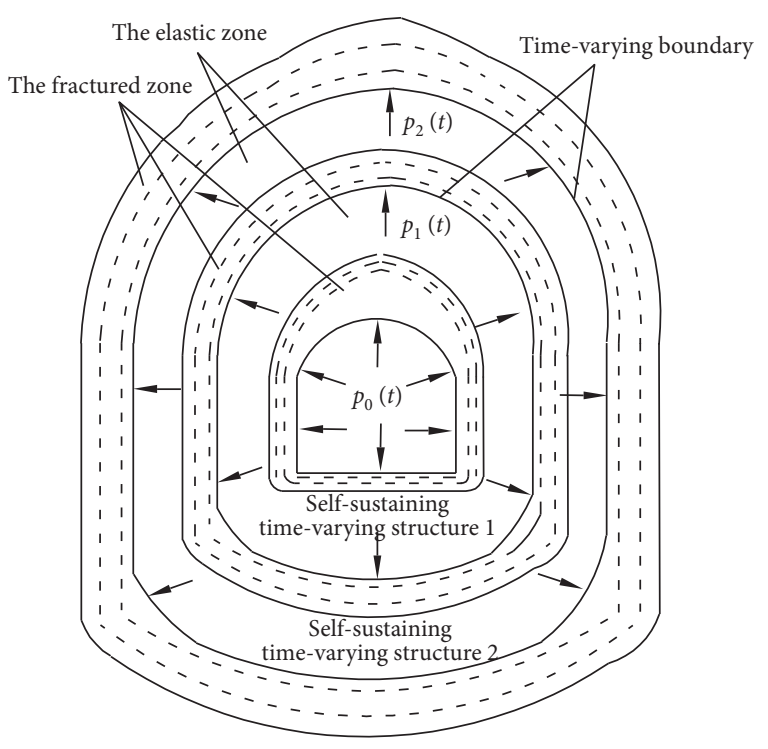

FIGURE 4: Distribution of self-sustaining time-varying structures of the surrounding rocks.

TABLE 1: The width and quantity of fractured zone when excavation time is $1 \mathrm{~s}$ [35].

\begin{tabular}{lccccc}
\hline \multirow{2}{*}{$\sigma_{c}$} & Radius/m & \multicolumn{5}{c}{ Numbers of fractured zone } \\
& & 1 & 2 & 3 & 4 \\
\hline \multirow{2}{*}{$\sigma_{c}=80 \mathrm{MPa}$} & $R_{0}$ & 4.000 & 4.796 & 5.803 & 6.500 \\
& $R_{1}$ & 4.590 & 5.338 & 5.930 & 6.500 \\
& $R_{1}-R_{0}$ & 0.586 & 0.542 & 0.127 & 0.000 \\
$\sigma_{c}=90 \mathrm{MPa}$ & $R_{0}$ & 4.000 & 4.756 & 5.610 & \\
& $R_{1}$ & 4.476 & 5.129 & 5.610 & \\
$\sigma_{c}=100 \mathrm{MPa}$ & $R_{1}-R_{0}$ & 0.474 & 0.373 & 0.000 & \\
\hline
\end{tabular}

number of self-sustaining time-varying structures increases, and the thickness is also different.

\section{Rockburst Occurrence Mechanism Induced by the Adjustment of Self-Sustaining Time-Varying Structure of the Surrounding Rock}

3.1. Dynamic Characteristics of Self-Sustaining Time-Varying Structures of the Surrounding Rock. Considering the complexity of time-varying structure and facilitating the analysis of the rockburst occurrence mechanism induced by the adjustment of self-sustaining time-varying structures of the surrounding rock, the spatial structure of underground surrounding rock can be simplified as a plane strain problem, and self-sustaining time-varying structures of the surrounding rock can be regarded as a single degree of freedom nonperiodic time-varying system. Then, the typical particles in the system, such as shape geometric center, mass center at the initial time, can be selected and analyzed.

Assuming the mass of the particle and the velocity is $m(t)$ and $v(t)$ at the time $t$, then the momentum of the system is $m(t) v(t)$ at the time $t$. Assuming the mass of the
TABLE 2: The width and quantity of fractured zone when excavation time is 100 s [35].

\begin{tabular}{lccccc}
\hline \multirow{2}{*}{$\sigma_{c}$} & Radius/m & \multicolumn{5}{c}{ Numbers of fractured zone } \\
& & 1 & 2 & 3 & 4 \\
\hline \multirow{2}{*}{$\sigma_{c}=60 \mathrm{MPa}$} & $R_{0}$ & 4.000 & 4.983 & 6.041 & 0.652 \\
& $R_{1}$ & 4.965 & 5.958 & 6.109 & 0.652 \\
& $R_{1}-R_{0}$ & 0.965 & 0.975 & 0.068 & 0.000 \\
$\sigma_{c}=80 \mathrm{MPa}$ & $R_{0}$ & 4.000 & 4.800 & 5.704 & 0.602 \\
& $R_{1}$ & 4.650 & 5.325 & 5.768 & 0.602 \\
& $R_{1}-R_{0}$ & 0.650 & 0.525 & 0.064 & 0.000 \\
$\sigma_{c}=90 \mathrm{MPa}$ & $R_{0}$ & 4.000 & 5.753 & 7.313 & \\
& $R_{1}$ & 4.463 & 6.116 & 7.313 & \\
$\sigma_{c}=100 \mathrm{MPa}$ & $R_{1}-R_{0}$ & 0.462 & 0.363 & 0.000 & \\
\hline
\end{tabular}

TABLE 3: The width and quantity of fractured zone when excavation time is 1000 s [35].

\begin{tabular}{lcccc}
\hline \multirow{2}{*}{$\sigma_{c}$} & Radius $/ \mathrm{m}$ & \multicolumn{4}{c}{ Numbers of fractured zone } \\
& & 1 & 2 & 3 \\
\hline \multirow{2}{*}{$\sigma_{c}=60 \mathrm{MPa}$} & $R_{0}$ & 4.000 & 5.653 & 0.755 \\
& $R_{1}$ & 5.506 & 6.657 & 0.755 \\
& $R_{1}-R_{0}$ & 1.501 & 1.004 & 0.000 \\
$\sigma_{c}=80 \mathrm{MPa}$ & $R_{0}$ & 4.000 & 5.107 & 0.746 \\
& $R_{1}$ & 5.024 & 6.109 & 0.746 \\
& $R_{1}-R_{0}$ & 1.022 & 1.022 & 0.000 \\
$\sigma_{c}=90 \mathrm{MPa}$ & $R_{0}$ & 4.000 & 5.964 & \\
& $R_{1}$ & 5.815 & 5.964 & \\
$\sigma_{c}=100 \mathrm{MPa}$ & $R_{1}-R_{0}$ & 1.814 & 0.000 & \\
\hline
\end{tabular}

system decreases with time, the mass, the velocity, and the absolute velocity of the unit mass given out are, respectively, set as $m(t)-|\mathrm{d} m|, v+d v$ and $u$ at time $t+\mathrm{d} t$, then the momentum of the system at time $t+\mathrm{d} t$ is $[m(t)-|\mathrm{d} m|](v+\mathrm{d} v)+u|\mathrm{~d} m|$. Therefore, equation (1) can be obtained by the momentum theorem of the particle system.

$$
\begin{gathered}
\{[m(t)-|\mathrm{d} m|](v+\mathrm{d} v)+u|\mathrm{~d} m|\}-m(t) v(t) \\
=[P(t)-D(t) v(t)-K(t) X(t)] \mathrm{d} t,
\end{gathered}
$$

where $[X(t)]$ is the system displacement at time $t ;[K(t)]$ is the system stiffness at time $t ;[D(t)]$ is the system damping at time $t ;[P(t)]$ is the system external load at time $t$.

By omissions of high-order trace and noting that $(\mathrm{d} m / \mathrm{d} t)$ is negative, the forced vibration equation of a timevarying system with a single degree of freedom is obtained [36]. That is,

$$
\begin{array}{r}
m(t) \frac{\mathrm{d}^{2} X(t)}{\mathrm{d} t^{2}}+\frac{\mathrm{d} m(t)}{\mathrm{d} t}\left[\frac{\mathrm{d} X(t)}{\mathrm{d} t}-u(t)\right]+D(t) \frac{\mathrm{d} X(t)}{\mathrm{d} t} \\
+K(t) X(t)=P(t) .
\end{array}
$$

When the mass of the system increases with time, the motion equation can also be deduced as equation (2). 
With free vibration, let $[P(t)]=0$; at the same time, in the elastic brittleness field, the influence of damping is not considered, then let $[D(t)]=0$; in many cases, $u(t)$ is very small relative to $v(t)$, which is $(\mathrm{d} X(t) / \mathrm{d} t)$, and you can let $u(t)=0$. Equation (5) can be obtained. That is,

$$
m(t) \frac{\mathrm{d}^{2} X(t)}{\mathrm{d} t^{2}}+\frac{\mathrm{d} m(t)}{\mathrm{d} t} \frac{\mathrm{d} X(t)}{\mathrm{d} t}+K(t) X(t)=0 .
$$

Time variability considered, the vibration equation of time-varying structural system can be expressed as equation (6) [36]. That is,

$$
[M(t)]\{\ddot{U}(t)\}+[C(t)]\{\dot{U}(t)\}+[K(t)]\{U(t)\}=\{F(t)\},
$$

where $[M(T)]$ is the time-dependent structure mass matrix; $[C(t)]$ is the time-dependent damping matrix; $[K(t)]$ is the time-dependent stiffness matrix; $\{F(t)\}$ is the load of timevarying structure; $\{U(t)\}$ is the response body of the timevarying structure.

Compared with equation (5), $(\mathrm{d} m / \mathrm{d} t)$ in equation (5) is equivalent to the viscous damping coefficient and $(\mathrm{d} m / \mathrm{d} t)$ has the following two situations. (1) When the mass increases with time, which is $(\mathrm{d} m / \mathrm{d} t)>0$, the system is equivalent to having positive damping. When the $(\mathrm{d} m / \mathrm{d} t)$ is large, the system cannot vibrate freely. (2) When the mass decreases with time, which is $(\mathrm{d} m / \mathrm{d} t)<0$, the system is equivalent to having negative damping. At this time, the system may have a free vibration with increasing amplitude. $(\mathrm{d} m / \mathrm{d} t)$ is the rate of mass change with time of the selfsustaining time-varying structure of the surrounding rock, which can be positive or negative.

\subsection{Mechanical Model of the Rockburst Induced by Self-} Sustaining Time-Varying Structure of the Surrounding Rock. Rockburst is related to the dynamic instability of the surrounding rock after excavation. Based on the above analysis, when the mass of the time-varying system changes with time, the dynamic response of the system will be affected greatly. When the mass decreases with time, the unstable dynamic system with negative damping will be formed, which is $(\mathrm{d} m / \mathrm{d} t)<0$ which may induce rockburst. It provides a new way to study the rockburst by judging the increase or decrease of the structural system mass. Here, the mass change is for the self-sustaining time-varying structure, because the mass of the whole underground structure is unchanged. $(\mathrm{d} m / \mathrm{d} t)<0$ can be the condition of rockburst. The system mass change is caused by the surrounding rock fragmentation, which will lead to the surrounding rock volume expansion. It requires the surrounding rock to have expansion space. Therefore, the mechanical model shown in Figure 5 can be established.

The mechanical model shows that the expansion space is mainly in two places, the contact boundary of each timevarying structure $(\mathrm{d} m)$ and the free surface of the roadway $\left(\mathrm{d} m^{\prime}\right)$. The rock in these two places $\left(\mathrm{d} m\right.$ and $\left.\mathrm{d} m^{\prime}\right)$, which is the shaded part in Figure 5, is in a uniaxial or biaxial stress state prone to failure than the other areas. The failure degree of the free surface $\left(\mathrm{d} m^{\prime}\right)$ and the time-varying structure boundary $(\mathrm{d} m)$ is different. Under high stress, $d m^{\prime}$ rock is prone to loss of bearing capacity completely in partial place, leaving time-varying structure 1, turning time-varying structure 1 into a dynamically unstable system. Meanwhile, the stress peak of surrounding rock moves from the free surface to the interior, which is the stress transition from the initial state $(b)$ to the intermediate state $(c)$ in Figure 2. Although the rock $(\mathrm{d} m)$ is damaged, it still has some bearing capacity. It will break away from the elastic zone of timevarying structure 1 and become part of the fractured zone of time-varying structure 2 . The bearing capacity of timevarying structure 2 is strengthened, while time-varying structure 1 becomes a dynamically unstable system. Once its mass parameters change rapidly, or there is an external disturbance, it will be accompanied by violent vibration and induce rockburst.

3.3. Discussion of $(d m / d t)$. Since the self-sustaining structure is composed of the fractured zone and the elastic zone, the structural stability is based on the premise that the amount of the fractured zones and the elastic zones keeps a certain proportion. The increase and decrease of the selfsustaining structure $m(t)$ can be identified by confirming whether the rock in the two zones can bear the load. Under high stress, if the rock in the two zones fails or softens, it does not have the bearing capacity to become the main bearing structure. Then, it breaks away from the time-varying structure, and the mass of the self-staining system decreases. Following, rockburst occurs. Therefore, it is necessary to determine a suitable index to measure the rock bearing strength. Generally, the elastic modulus $E$ is used to measure the rock bearing strength.

Under excavation unloading conditions, the surrounding rock of the roadway will be in uniaxial or biaxial stress state instead of the triaxial stress state. You [37] compared the triaxial compressive strength, uniaxial compressive strength, and elastic modulus $E$ of different rocks, as shown in Table 4 . Literatures $[38,39]$ have a similar study. The linear relationship between elastic modulus $E$ and strength is consistent in statistics. The uniaxial compression results further indicate that the improvement of elastic modulus $E$ is rooted in the material bearing capacity increase.

Yang et al. [40] obtained that, under the action of confining pressure, the rock (coal) stiffness increases, then the elastic modulus increases, as shown in Figure 6 . Wawersik and Brace [41] gave the triaxial compression curve of the granite sample. In the range of confining pressure up to $153 \mathrm{MPa}$, the elastic modulus still increases with the confining pressure. Song et al. obtained a similar conclusion by a laboratory test [42]. Lai [43] also obtained the same conclusion by testing the elastic modulus and confining pressure of the marble and fine sandstone. Literature [44] analyzed the test results of middle fine sandstone and sandy mudstone samples in the Permian coal-bearing rock series in the XinJi well field, Huainan. It concluded that the elastic modulus of sedimentary rocks grows with the increase of confining pressure, which presented a nonlinear 


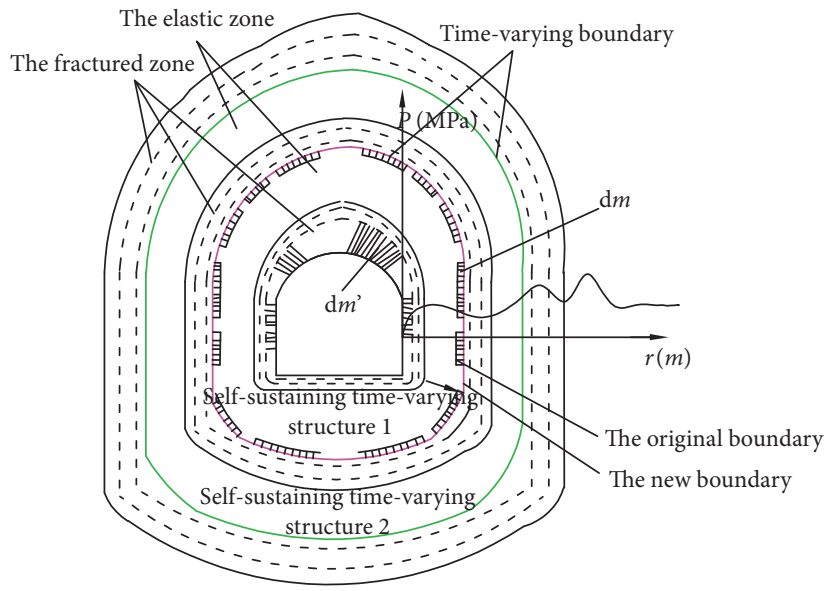

FIgURE 5: Mechanical model for rockburst based on time-varying structure.

TABle 4: Compressive strength $\sigma_{c}(\mathrm{MPa})$ and elastic modulus $E(\mathrm{GPa})$ of different rocks [37].

\begin{tabular}{|c|c|c|c|c|c|c|c|c|c|}
\hline \multirow{2}{*}{ Sample } & & \multicolumn{8}{|c|}{ Confining pressure $(\mathrm{MPa})$} \\
\hline & & 0 & 0 & 0 & 0 & 1 & 5 & 10 & 15 \\
\hline \multirow{2}{*}{ Medium-coarse sandstones } & $\sigma_{c}$ & 163 & 129 & 179 & 121 & 160 & 182 & 230 & 280 \\
\hline & $E$ & 19.8 & 14 & 22 & 13.5 & 19 & 22 & 26.5 & 31.5 \\
\hline \multirow{2}{*}{ Siltstone } & $\sigma_{c}$ & 154 & 100 & 80 & 60 & 82 & 106 & 130 & 149 \\
\hline & E & 17.4 & 10 & 9.7 & 7.9 & 8.5 & 10 & 15 & 18.5 \\
\hline \multirow{2}{*}{ Fine siltstone } & $\sigma_{c}$ & 30.6 & 53.6 & 37.4 & 30 & 34 & 51 & 98 & 115 \\
\hline & $E$ & 4.1 & 6.5 & 3.9 & 4.5 & 4.9 & 6.5 & 12.8 & 14 \\
\hline \multirow{2}{*}{ Siltstone } & $\sigma_{c}$ & 71.4 & 60 & 66 & 60 & 64 & 79 & 120 & 150 \\
\hline & $E$ & 6.1 & 7.9 & 9.5 & 7.5 & 7.2 & 8.1 & 13 & 18 \\
\hline \multirow{2}{*}{ Medium-coarse sandstones } & $\sigma_{c}$ & 146 & 57.1 & 160 & 110 & 125 & 160 & 230 & 245 \\
\hline & $E$ & 16 & 6.6 & 20.7 & 12.5 & 14.6 & 19 & 24 & 28 \\
\hline \multirow{2}{*}{ Fine sandstones } & $\sigma_{c}$ & 18.3 & 73.9 & 181 & 18 & 21 & 334 & 66 & 89 \\
\hline & $E$ & 2.9 & 8 & 24 & 2.5 & 2.9 & 4.1 & 8.5 & 9.6 \\
\hline \multirow{2}{*}{ Bauxites } & $\sigma_{c}$ & 81 & 128 & 76 & 66 & 89 & 115 & 140 & 210 \\
\hline & $E$ & 9.6 & 14 & 9.2 & 6.9 & 7.8 & 11 & 12.5 & 19 \\
\hline
\end{tabular}

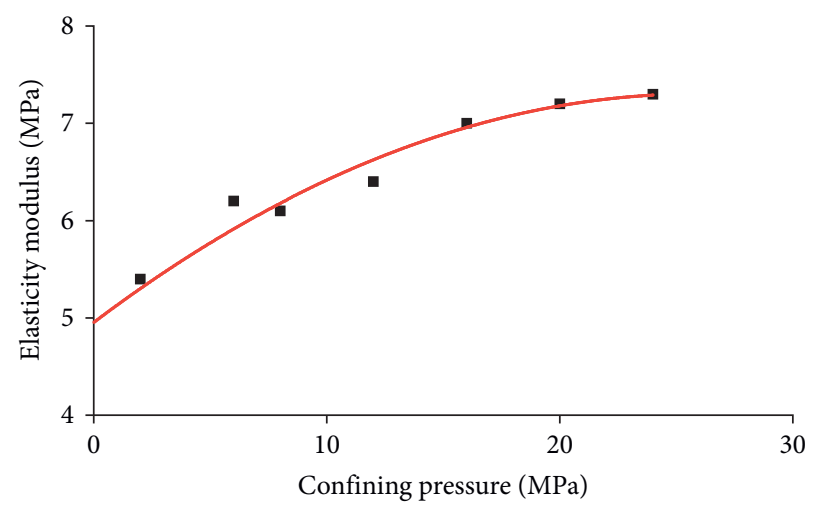

Figure 6: The relation between elastic modulus and confining pressure of coal sample.

relationship. In literature [45], to study the problem of water inrush in the coal mine, rock samples of coal seam floor with a depth of $150 \mathrm{~m}$ were tested. In the range of $0 \sim 15 \mathrm{MPa}$, the average modulus growth with the confining pressure increases. It can be concluded from the above studies that the elastic modulus $E$ increase is a phenomenon of rock (coal) bearing capacity improvement.

On the contrary, in this paper, the elastic modulus $E$ decrease can be used to illustrate the reduction of confining pressure or uniaxial compressive strength, so as to describe 
the failure or softening of the rock (coal), and the proportion change of the fractured zone (softened zone) and elastic zone in the self-sustaining structure. The mass $m(t)$ of the selfsustaining structure near the roadway is reduced, which is transformed into a dynamic unstable system, and rockburst may occur. The elastic modulus $E$ change is very important to the self-sustaining of the structure system. It is a new idea to explain rockburst mechanism and prevent rockburst by adjusting elastic modulus $E$ to change the self-sustaining structure mass $m(t)$.

Pan and Zhang [46] put forward the concept of the critical softened zone depth. For the coal face, the critical softening zone depth can be expressed as equation (7). That is,

$$
\rho^{*}=\frac{1}{2 a} \ln \frac{\left(E_{\lambda} / E\right)+1}{\left(E_{\lambda} / E\right)-(1 / 16)\left(E_{d} / E\right) a^{4} h^{3} H},
$$

where $a$ is the excavation footage of the roadway or working face; $E$ is the elastic modulus of coal before the peak strength; $E_{\lambda}$ is the reduced modulus of coal after the peak strength; $h$ is the thickness of the roof; $E_{d}$ is the elastic modulus of the roof; $H$ is the thickness of coal seam.

According to equation (7), Figure 7 can be drawn.

The critical softened depth of circular roadway is defined as [46]

$$
R^{*}=R \sqrt{1+\frac{E}{E_{\lambda}}}
$$

where $E$ is the elastic modulus of coal before the peak strength; $E_{\lambda}$ is the reduced modulus of coal after the peak strength; $R$ is the radius of the circular roadway.

From equations (7) and (8), when $\left(E / E_{\lambda}\right)$ increases $(E$ increases or $E_{\lambda}$ decreases), the brittleness of rock (coal) is weak, and the plastic deformation increases. Then, the corresponding critical softened zone is deeper, and the rockburst in deep mining is harmless. At this time, it is equivalent to exert the bearing capacity of the softened zone in the self-sustaining time-varying structure. Therefore, making $\left(E / E_{\lambda}\right)$ larger and increasing the plastic deformation after the peak can prevent rockburst.

In the literature [47-58], it is proposed to use measures to alleviate rockburst intensity, such as large-diameter drilling to increase fractures and water injection to rock (coal) seams. These measures increase the plastic deformation of the rock (coal) seams after the peak, then $E_{\lambda}$ becomes smaller and $\left(E / E_{\lambda}\right)$ becomes larger. From the perspective of the self-sustaining time-varying structure, large-diameter drilling increases the fractured zone mass of the self-sustaining structure by making fractures, and water injection to rock (coal) seams also increases the mass of the self-sustaining system. All these measures are to make $(\mathrm{d} m / \mathrm{d} t)>0$ of the self-sustaining system to prevent and control rockburst. The guiding idea of controlling rockburst with $(\mathrm{d} m / \mathrm{d} t)>0$ of self-sustaining time-varying structure is consistent with the commonly used measures to control rockburst.
3.4. Application of $(d m / d t)$. When $(\mathrm{d} m / \mathrm{d} t)<0$, the system will have a rockburst. Conversely, preventing rockburst can be achieved by increasing the mass $m(t)$ of the self-sustaining structure. Artificial measures are adopted to reduce the bearing capacity of the partial surrounding rock, as long as the range of self-sustaining structure in the corresponding softening zone can be increased (the structure mass can be increased). It can become the idea of preventing rockburst. Chen et al. [59] carried out a systematic numerical simulation of roof pressure unloading of 6303 working face in Jisan Colliery. The results showed that the danger of rockburst was reduced through the connection of the fracture circle.

The change speed of $(\mathrm{d} m / \mathrm{d} t)$ can distinguish the intensity of rockburst, which depends on rock brittleness and construction technology. The brittle rock will be destroyed instantly when it has a small deformation, and it leads the structure mass parameters of self-sustaining time-varying structure to change rapidly. The negative damping is large, and the rockburst is more intense. Rockburst in hard rock is more intense than rockburst in low-strength rock [60] because the brittleness of hard rock is generally larger. A research in literature [61] also obtained a consistent conclusion, as shown in Table 5. On the contrary, the possibility and intensity of rockburst in dry areas are greater than those in water areas, because the rock parameters, rock strength, and brittleness in water areas weaken generally.

Xie et al. [62] selected the 1\# diversion tunnel (TBM excavation) and 2\# diversion tunnel (blasting excavation) with the same geological conditions and lithology of Jin-ping II Hydropower Station to conduct rockburst monitoring and statistics, and the results showed that there was a high grade rockburst in blasting excavation, as shown in Table 6 and Figure 8 . The mass change rate $(\mathrm{d} m / \mathrm{d} t)$ during blasting excavation is greater than that in TBM excavation, so blasting excavation is more likely to occur high-intensity rockburst than TBM excavation.

During the excavation of the Jin-ping II Hydropower Station in China, several violent rockburst occurred. Summarizing the rockburst prevention measures of this station, combining with ground stress state monitoring and surrounding rock blasting tendency monitoring, Yan et al. [63] studied the rockburst spatial distribution on the deep roadway axis and the statistical characteristics of rockburst around the working face. The results indicate that the stress state and brittleness of the surrounding rock are the main factors affecting the rockburst development. Reducing the surrounding rock stiffness by stress-relief blasting method and reducing the excavation footage can effectively control the possibility and intensity of the rockburst. All these measures are to reduce the change speed of $(\mathrm{d} m / \mathrm{d} t)$, including the flexible support after tunnel excavation.

When $(\mathrm{d} m / \mathrm{d} t)<0$, the system has negative damping, and the system may produce free vibration with increasing amplitude. The faster the $(\mathrm{d} m / \mathrm{d} t)$ changes, the more intense the rockburst occurs. It indicates that the energy of rockburst may come from the lithology and rock stress state. 


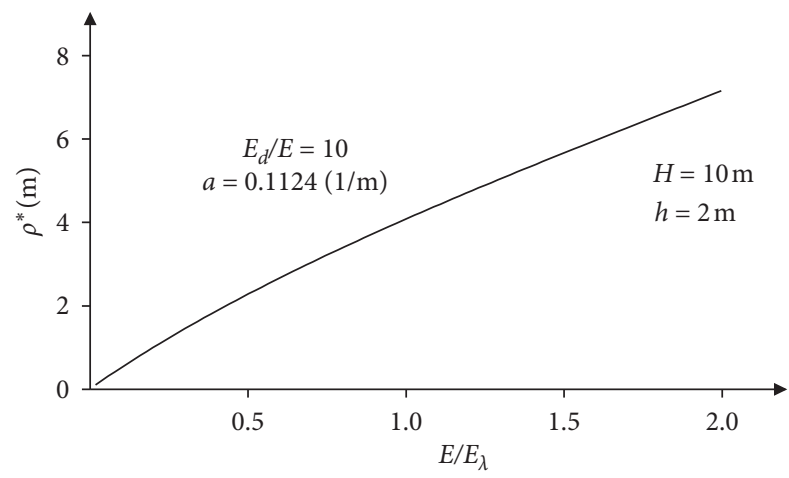

FIGURE 7: The relationship of $\rho^{*}$ and $\left(E / E_{\lambda}\right)[46]$.

TABLE 5: The relationship between rock brittleness index and rockburst intensity [61].

\begin{tabular}{|c|c|c|c|c|}
\hline Rock brittleness index & $0 \sim 4.0$ & $3.5 \sim 5.5$ & $5.0 \sim 7.8$ & $>7.0$ \\
\hline Rockburst intensity & None & Weak & Medium & Violent \\
\hline
\end{tabular}

TABLE 6: Rockburst statistical results [62].

\begin{tabular}{lccccc}
\hline \multirow{2}{*}{ Monitoring stake number } & Excavation method & \multicolumn{3}{c}{ Rockburst frequency } \\
& & Weak rockburst & Medium rockburst & Violent rockburst & Very violent rockburst \\
\hline $1 \# 10,000-17,000$ & TBM excavation & 67 & 12 & 0 & 0 \\
$2 \# 10,000-17,000$ & Blasting excavation & 54 & 17 & 3 & 1 \\
\hline
\end{tabular}

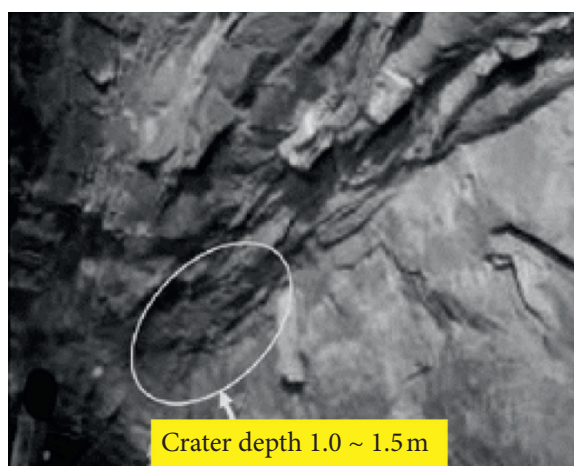

(a)

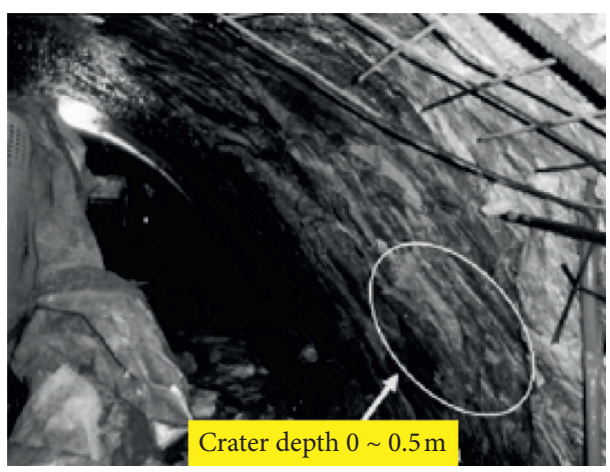

(b)

FIGURE 8: Surface of diversion tunnel after excavation [62]. (a) Blasting excavation. (b) TBM excavation.

Meanwhile, this explains well the situation mentioned in the introduction section that $\left(\sigma_{\theta} / \sigma_{c}\right)$ does not meet the Russenes criterion when the two tunnels, Qinling tunnel and Taipingyi diversion tunnel, have strong rockburst.

\section{Conclusion}

The rockburst problem has the characteristics that internal structural parameters of time-varying structural mechanics change with time. In this paper, the concept of "self-sustaining time-varying structure of the surrounding rock" is proposed, and the time-varying structure dynamics theory is applied to the study on the rockburst occurrence mechanism.
(1) The concept of "self-sustaining time-varying structure of the surrounding rock" is proposed. The surrounding rock of the excavation roadway has a self-sustaining structure with bearing capacity, and the internal parameters of the self-sustaining structure (including geometric shape, physical characteristics, and boundary state) are time-varying. The number and thickness of the self-sustaining time-varying structure depend on the in situ stress, roadway excavation duration, and surrounding rock lithology.

(2) The self-sustaining time-varying structure of the surrounding rock is simplified to a plane strain 
problem, which is regarded as a nonperiodic timevarying system with a single degree of freedom. And the dynamic characteristics of the self-sustaining time-varying structure of surrounding rock are analyzed by the momentum theorem of the particle system. The results show that when the mass of the surrounding rock self-sustaining time-varying structure changes with time and $(\mathrm{d} m / \mathrm{d} t)<0$, the system will have negative damping, and a dynamically unstable system will be formed. At this time, the system may have a free vibration with increasing amplitude, and rockburst will occur.

(3) When $(\mathrm{d} m / \mathrm{d} t)<0$, rockburst may occur in the system. The faster the $(\mathrm{d} m / \mathrm{d} t)$ changes, the more intense the rockburst occurs. It indicates that the energy of rockburst may come from the rock lithology and stress state. It explains the rockburst occurrence mechanism from a new sight.

(4) From the view of the self-sustaining time-varying structure of the surrounding rock, making $(\mathrm{d} m / \mathrm{d} t)>0$ can achieve the purpose of preventing and controlling rockburst by the measures, which can increase the rock mass in the softening zone, such as water injection and increasing cracks in the strata (coal seam). Reducing the cyclic excavation footage, improving construction techniques, and other measures to reduce the speed of $(\mathrm{d} m / \mathrm{d} t)$ can effectively reduce the rockburst intensity.

\section{Symbol List}

$\begin{array}{ll}W_{m}: & \text { The rock failure energy } \\ W_{m}: & \text { The energy released by the surrounding rock } \\ \sigma_{\theta}: & \text { Tangential stress of roadway surrounding rock } \\ \sigma_{c}: & \text { Compressive strength } \\ \sigma_{r}: & \text { Radial stress } \\ \sigma_{v}: & \text { The vertical crustal stress } \\ \sigma_{h}: & \text { The horizontal crustal stress } \\ \alpha, \beta: & \text { Stress concentration factor } \\ K: & \text { Side pressure coefficient } \\ R: & \text { Spherical roadway radius } \\ q: & \text { In situ stress } \\ v_{0}: & \text { Poisson ratio } \\ E: & \text { The elastic modulus } \\ \beta_{0}: & \text { Dynamic friction angle } \\ R_{0}: & \text { The inner boundary of the fractured zone } \\ R_{1}: & \text { The outer boundary of the fractured zone } \\ R_{1}-R_{0}: & \text { The width of the fractured zone } \\ m(t): & \text { The mass of the particle at the time } \mathrm{t} \\ v(t): & \text { The velocity of the particle at the time } \mathrm{t} \\ {[X(t)]:} & \text { The displacement of the system at time } \mathrm{t} \\ {[K(t)]:} & \text { The stiffness of the system at time } \mathrm{t} \\ {[D(t)]:} & \text { The damping of the system at time } \mathrm{t} \\ {[P(t)]:} & \text { The external load of the system at time } \mathrm{t} \\ {[M(t)]:} & \text { The time-dependent structure quality matrix } \\ {[C(t)]:} & \text { The time-dependent damping matrix } \\ {[K(t)]:} & \text { The time-dependent stiffness matrix } \\ \{F(t)\}: & \text { The load of time-varying structure } \\ & \end{array}$

$\{U(t)\}: \quad$ The response body of time-varying structure.

$(\mathrm{d} m / \mathrm{d} t)$ : The rate of mass change with time of the selfsustaining time-varying structure of surrounding rock

a: $\quad$ The excavation footage of the roadway or working face

$E_{\lambda}$ : The reduced modulus of coal after the peak strength

$h: \quad$ The thickness of the roof

$E_{d}$ : The elastic modulus of the roof

$H: \quad$ The thickness of coal seam

$R^{*}$ : The critical softened depth of circular roadway.

\section{Data Availability}

The data used to support the findings of this study are available from the corresponding author.

\section{Conflicts of Interest}

The authors declare that they have no conflicts of interest.

\section{Acknowledgments}

The work was supported by the National Natural Science Foundation of China (Grant nos. 51674116, 51474103, and 51904101) and Natural Science Foundation of Hunan Province (Grant nos. 2020JJ4311 and 2020JJ5188). This support is gratefully acknowledged.

\section{References}

[1] P. K. Kaiser, D. D. Tannant, and D. R. McCreath, Canadian Rockburst Support Handbook, Geomechanics Research Centre, Sudbury, Canada, 1996.

[2] A. Mazaira and P. Konicek, "Intense rockburst impacts in deep underground construction and their prevention," $\mathrm{Ca}$ nadian Geotechnical Journal, vol. 52, no. 10, pp. 1426-1439, 2015.

[3] X. Li, F. Gong, M. Tao et al., "Failure mechanism and coupled static-dynamic loading theory in deep hard rock mining: a review," Journal of Rock Mechanics and Geotechnical Engineering, vol. 9, no. 4, pp. 767-782, 2017.

[4] S. Wang, L. Huang, and X. Li, "Analysis of rockburst triggered by hard rock fragmentation using a conical pick under high uniaxial stress," Tunnelling and Underground Space Technology, vol. 96, p. 103195, 2020.

[5] X.-T. Feng, B. R. Chen, G. Feng, Z. Zhao, H. Zheng, and M. Heib, "Description and engineering phenomenon of rockbursts," in Rockburst: Mechanisms, Monitoring, Warning, and Mitigation, pp. 3-26, Elsevier, Amsterdam, Netherlands, 2017.

[6] L.-m. Dou, C.-p. Lu, Z.-1. Mu, and M.-s. Gao, "Prevention and forecasting of rock burst hazards in coal mines," Mining Science and Technology (China), vol. 19, no. 5, pp. 585-591, 2009.

[7] Z. Yang, C. Liu, S. Tang, L. Dou, and J. Cao, "Rock burst mechanism analysis in an advanced segment of gob-side entry under different dip angles of the seam and prevention technology," International Journal of Mining Science and Technology, vol. 28, no. 6, pp. 891-899, 2018. 
[8] G. Zhao, D. Wang, B. Gao, and S. Wang, "Modifying rock burst criteria based on observations in a division tunnel," Engineering Geology, vol. 216, pp. 153-160, 2017.

[9] L. Dou, W. Cai, A. Cao, and W. Guo, "Comprehensive early warning of rock burst utilizing microseismic multi-parameter indices," International Journal of Mining Science and Technology, vol. 28, no. 5, pp. 767-774, 2018.

[10] Z. Liang, R. Xue, N. Xu, and W. Li, "Characterizing rockbursts and analysis on frequency-spectrum evolutionary law of rockburst precursor based on microseismic monitoring," Tunnelling and Underground Space Technology, vol. 105, Article ID 103564, 2020.

[11] W. D. Ortlepp and T. R. Stacey, "Rockburst mechanisms in tunnels and shafts," Tunnelling and Underground Space Technology, vol. 9, no. 1, pp. 59-65, 1994.

[12] W. Blake, "Rockburst mechanics," Colorado School of Mines Quarterly, vol. 67, pp. 1-64, 1972.

[13] P. K. Kaiser and M. Cai, "Design of rock support system under rockburst condition," Journal of Rock Mechanics and Geotechnical Engineering, vol. 4, no. 3, pp. 215-227, 2012.

[14] J. Xu, J. Jiang, N. Xu, Q. Liu, and Y. Gao, “A new energy index for evaluating the tendency of rockburst and its engineering application," Engineering Geology, vol. 230, pp. 46-54, 2017.

[15] A. Kidybiński, "Bursting liability indices of coal," International Journal of Rock Mechanics and Mining Sciences and Geomechanics Abstracts, vol. 18, pp. 295-304, 1981.

[16] H. Mitri, B. Tang, and R. Simon, "FE modelling of mininginduced energy release and storage rates," Journal of The South African Institute of Mining and Metallurgy, vol. 99, pp. 103110, 1999.

[17] M. Kwasniewski and J. Wang, "3-D numerical modeling and study of mine tremors associated with coal mining in the vicinity of major faults," An Extended Abstract, vol. 22, pp. 351-364, 1999.

[18] J.-A. Wang and H. D. Park, "Comprehensive prediction of rockburst based on analysis of strain energy in rocks," Tunnelling and Underground Space Technology, vol. 16, no. 1, pp. 49-57, 2001.

[19] L. Peng, Z. Yanbo, T. Baozhu, Y. Xulong, S. Lin, and L. Xiangxin, "Experimental study on energy evolution characteristics in the process of tunnel rockbursts," Chinese Journal of Rock Mechanics and Engineering, vol. 38, pp. 736-746, 2019.

[20] X. linsheng, "Research of rockburst formation condition in underground engineering," Journal of Chongqing Jiaotong University, vol. 24, pp. 31-34, 2005.

[21] X. Zemin, H. Runqiu, L. Xingchun, L. Rui, and S. Jingyi, "Limitaions of static load theory in rockburst research and preliminary analysis on dynamics mechanism of rockburst," Chinese Journal of Rock Mechanics and Engineering, vol. 22, pp. 1255-1262, 2003.

[22] Z. Xu, R. Huang, Z. Fan, and P. Wu, "Progress in research on rock burst hazard of long tunnel with large section," Journal of Natural Disasters, vol. 13, pp. 16-25, 2004.

[23] Z. Cao, "Time-variation mechanics and its applition in engineering," Mechanics in Engineering, vol. 21, pp. 1-5, 1999.

[24] L. Wang, "Construction mechanics and time-varying mechanics in civil engineering analysis," in Proceedings of the 2016 4th International Conference on Machinery, Materials and Information Technology Applications (ICMMITA 2016), pp. 1163-1166, Computer Science and Electronic Technology International Society, Xi'an, China, December 2016.

[25] Q.-y. Zhang, M.-y. Ren, K. Duan et al., "Geo-mechanical model test on the collaborative bearing effect of rock-support system for deep tunnel in complicated rock strata," Tunnelling and Underground Space Technology, vol. 91, p. 103001, 2019.

[26] L. Yourong and W. Lansheng, Rock Mechanics, China University of Geosciences Press, Wuhan, China, 1999.

[27] H. Faliang, L. Xiaoming, and W. Minqiang, "Re-analysis of rockburst genesis and discussion on intensity division," in Proceedings of the the Third National Conference on Rock Dynamics, pp. 448-457, Guilin, China, October 1992.

[28] M. He, J. Miao, and J. li, "Experimental study on rockburst processes of granite specimen at great depth," Chinese Journal of Rock Mechanics and Engineering, vol. 26, pp. 865-876, 2007.

[29] M. He, "Rock mechanics and hazard control in deep mining engineering in China," in Proceedings of the Rock Mechanics in Underground Construction-The ISRM International Symposium 2006 and the 4th Asian Rock Mechanics Symposium, Singapore, November 2006.

[30] F. Zulie, "Tension and compression zone characteristics and primary and secondary load zonesmaintenance theory," in The Second Academic Conference of China Rock and Soft Rock Engineering Committee Beijing, Beijing, China, May 1999.

[31] J. Zou, K. Yu, and B. Yang, "Iethods of time-varying structural parameter identification," Advances In Mechanics, vol. 20, no. 3, pp. 370-377, 2000.

[32] Y. Li, Road Tunnel Brittle Rock Burst Mechanism and Simulation Research, University of Science and Technology Beijing, Beijing, China, 2015.

[33] X. Zhou, Q. Qian, B. Zhang, and Y. Zhang, "The mechanism of the zonal disintegration phenomenon around deep spherical tunnels," ENGINEERING MECHANICS, vol. 27, pp. 69-75, 2010.

[34] X. Chen, H. Shen, and S. Wang, "The research on theory and influence factors of self-sustaining structure of roadway surrounding rock," Journal of Liaoning Technical University(Natural Science), vol. 21, pp. 261-263, 2002.

[35] Z. Xiaoping and Q. Qihu, "Zonal fracturing mechanism IN deep tunnel," Chinese Journal of Rock Mechanics and Engineering, vol. 26, pp. 877-885, 2007.

[36] G. Li and Q. Li, Time-varying Reliability Theory of Engineering Structures and its Application, Science Press, Beijing, China, 2001.

[37] M. You, "Effect of confining pressure on the Young's modulus of rock specimen," Chinese Journal of Rock Mechanics and Engineering, vol. 22, pp. 53-61, 2003.

[38] K. Peng, Z. Liu, Q. Zou, Q. Wu, and J. Zhou, "Mechanical property of granite from different buried depths under uniaxial compression and dynamic impact: an energy-based investigation," Powder Technology, vol. 362, pp. 729-744, 2020.

[39] Q. Wu, L. Weng, Y. Zhao, F. Zhao, W. Peng, and S. Zhang, "Deformation and cracking characteristics of ring-shaped granite with inclusion under diametrical compression," Arabian Journal of Geosciences, vol. 13, p. 681, 2020.

[40] Y. Yang, Y. Song, and S. Chen, “Test study of coal's strength and deform ation characteristics under triaxial compression," Journal of China Coal Society, vol. 31, pp. 150-153, 2006.

[41] W. R. Wawersik and W. F. Brace, "Post-failure behavior of a granite and diabase," Rock Mechanics Felsmechanik Mècanique des Roches, vol. 3, no. 2, pp. 61-85, 1971.

[42] S. Song, X. Liu, Y. Tan, D. Fan, Q. Ma, and H. Wang, "Study on failure modes and energy evolution of coal-rock combination under cyclic loading," Shock and Vibration, vol. 2020, Article ID 5731721, 16 pages, 2020. 
[43] Y. Lai, "Effect analysis of confiinf pressure on Young's modulus," Journal of Chongqing Jiaotong University(Natural Science), vol. 28, pp. 246-249, 2009.

[44] Y. Su and S. Meng, Physical Theory and Method of Sedimentary Rocks, pp. 71-79, Science Press, Beijing, China, 2006.

[45] J. Wang and X. Xu, Research on Coal Mine Water Inrush Forecast, pp. 61-70, Geological Publishing House, Beijing, China, 1991.

[46] Y. Pan and M. Zhang, "The exact solution for rockburst in coal mine by unstability rockburst theory," Chinese Journal of Rock Mechanics and Engineering, vol. 15, pp. 504-510, 1996.

[47] W.-Y. Guo, T.-B. Zhao, Y.-L. Tan, F.-H. Yu, S.-C. Hu, and F.-Q. Yang, "Progressive mitigation method of rock bursts under complicated geological conditions," International Journal of Rock Mechanics and Mining Sciences, vol. 96, pp. 11-22, 2017.

[48] D. Ma, H. Duan, W. Liu, X. Ma, and M. Tao, "Water-sediment two-phase flow inrush hazard in rock fractures of overburden strata during coal mining," Mine Water and the Environment, vol. 39, no. 2, pp. 308-319, 2020.

[49] D. Ma, H. Duan, X. Li, Z. Li, Z. Zhou, and T. Li, "Effects of seepage-induced erosion on nonlinear hydraulic properties of broken red sandstones," Tunnelling and Underground Space Technology, vol. 91, p. 102993, 2019.

[50] D. Song, E. Wang, Z. Liu, X. Liu, and R. Shen, "Numerical simulation of rock-burst relief and prevention by water-jet cutting," International Journal of Rock Mechanics and Mining Sciences, vol. 70, pp. 318-331, 2014.

[51] Q. Wu, L. Chen, B. Shen, B. Dlamini, S. Li, and Y. Zhu, "Experimental investigation on rockbolt performance under the tension load," Rock Mechanics and Rock Engineering, vol. 52, no. 11, pp. 4605-4618, 2019.

[52] Q. Wu, X. Li, L. Weng, Q. Li, Y. Zhu, and R. Luo, "Experimental investigation of the dynamic response of prestressed rockbolt by using an SHPB-based rockbolt test system," Tunnelling and Underground Space Technology, vol. 93, p. 103088, 2019.

[53] Z.-T. Zhang, W.-H. Gao, X. Wang, J.-Q. Zhang, and X.-Y. Tang, "Degradation-induced evolution of particle roundness and its effect on the shear behaviour of railway ballast," Transportation Geotechnics, vol. 24, p. 100388, 2020.

[54] Z.-T. Zhang, W.-H. Gao, C.-F. Zeng, X.-Y. Tang, and J. Wu, "Evolution of the disintegration breakage of red-bed soft rock using a logistic regression model," Transportation Geotechnics, vol. 24, p. 100382, 2020.

[55] S. Li, S. Tian, W. Li, T. Yan, F. Bi, and S. Li, "Research on the resonance characteristics of rock under harmonic excitation," Shock and Vibration, vol. 2019, Article ID 6326510, 11 pages, 2019.

[56] M. Wang, W. Wan, and Y. Zhao, "Experimental study on crack propagation and the coalescence of rock-like materials with two preexisting fissures under biaxial compression," Bulletin of Engineering Geology and the Environment, vol. 79, no. 6, pp. 3121-3144, 2020.

[57] M. Wang and W. Wan, "A new empirical formula for evaluating uniaxial compressive strength using the Schmidt hammer test," International Journal of Rock Mechanics and Mining Sciences, vol. 123, p. 104094, 2019.

[58] F. Zhao, H. Wang, Z. Ye, Y. Liu, and Y. Li, "Study on energy consumption characteristics of different tools under impact load," Advances in Civil Engineering, vol. 2019, Article ID 3104102, 7 pages, 2019.
[59] G. Chen, L. Dou, and X. Xu, "Research on prevention of rock burst with relieving shot in roof," Procedia Engineering, vol. 45, pp. 904-909, 2012.

[60] S. Zhai, G. Su, S. Yin, B. Zhao, and L. Yan, "Rockburst characteristics of several hard brittle rocks: a true triaxial experimental study," Journal of Rock Mechanics and Geotechnical Engineering, vol. 12, no. 2, pp. 279-296, 2020.

[61] Z. Zhiqiang, G. Baoshu, and W. Hanmin, "Basic analysis of rock bursting occurrence condition," Journal of The China Railway Society, vol. 20, pp. 82-85, 1998.

[62] X. Liangtao, Y. Peng, L. Wenbo, C. Ming, and W. Gaohui, "Range prediction on the rock burst of deep-buried marble under different excavation methods," Journal of Vibration and Shock, vol. 38, pp. 31-39, 2019.

[63] P. Yan, Z. Zhao, W. Lu, Y. Fan, X. Chen, and Z. Shan, "Mitigation of rock burst events by blasting techniques during deep-tunnel excavation," Engineering Geology, vol. 188, pp. 126-136, 2015. 